\title{
ESTUDO REOLÓGICO DA GELIFICAÇÃO INDUZIDA PELO CALOR DE PROTEÍNAS DO SORO DO LEITE E DOS GÉIS RESULTANTES SOB CONDIÇÕES VARIADAS DE PH
}

\author{
Cristina T. ANDRADE , Rachel O. NASSER
}

\section{RESUMO}

Medidas reólogicas sob cisalhamento oscilatório foram realizadas em reômetro de tensão e deformação controladas com suspensões de concentrado de proteínas do soro do leite (WPC) a 10\% (m/m) em água e a diferentes condições de pH (pH 4,0, 4,6 e 7,0). O processo de gelificação induzida pelo calor foi investigado, assim como as propriedades viscoelásticas dos géis formados a $80^{\circ} \mathrm{C}$ e daqueles formados após o decréscimo da temperatura a $20^{\circ} \mathrm{C}$. Foi verificado que, em presença de teores significativos de sais, procedentes do próprio soro, a concentração usada nos experimentos foi suficiente para a formação de géis macroscópicos, e que o pH exerce papel importante na formação e na natureza estrutural dos géis.

Palavras-chave: reologia; concentrado de proteinas do soro do leite; gelificação; propriedades funcionais.

\section{SUMMARY}

RHEOLOGICAL CHARACTERIZATION OF THE HEAT-INDUCED GELATION OF WHEY PROTEINS AND OF THE RESULTING GELS UNDER VARIED pH CONDITIONS. Rheological measurements have been carried out in a controlled stress and strain rheometer on a whey proteins concentrate (WPC) at $10 \%(\mathrm{w} / \mathrm{w})$ in water and at different $\mathrm{pH}$ conditions (pH 4.0, 4.6 and 7.0). The heat-induced gelation process was investigated, as well as the viscoelastic properties of the gels formed at $80^{\circ} \mathrm{C}$ and those formed after decreasing the temperature to $20^{\circ} \mathrm{C}$. The results indicated that, in the presence of significant contents of salts from the whey sample, the concentration used in the experiments was sufficient for the formation of macroscopic gels, and that the $\mathrm{pH}$ exerts an important role on the formation and on the structural nature of the gels.

Keywords: rheology; whey proteins concentrate; gelation; functional properties.

\section{1 - INTRODUÇÃO}

O soro do leite bovino, fluido obtido após a transformação da caseína em queijo ou a sua remoção para a produção de caseinato ou outros ingredientes, consiste de uma mistura complexa de proteínas globulares $(\sim 0,6 \%)$, lipídios, minerais e lactose, em água (93\%) [9]. A secagem e a remoção de componentes não-protéicos, com o aumento da concentração em proteínas, levam a produtos comerciais, denominados concentrados (WPC, com 25 a $80 \%$ de proteínas) ou isolados (WPI, $\geq 90 \%$ de proteínas) de proteínas do soro do leite. Os WPC e WPI vêm sendo usados pela indústria alimentícia devido as suas propriedades nutricionais e funcionais. A $\beta$-lactoglobulina, proteína cujo teor no soro alcança 55-62\%, a $\alpha$-lactalbumina $(\sim 10 \%)$, as imunoglobulinas $(\sim 10 \%)$ e a albumina do soro do leite $(6 \%)$ constituem-se nas macromoléculas responsáveis pelas propriedades funcionais dos WPC e WPI, dentre as quais podem ser citadas as de agentes gelificantes, emulsificantes e estabilizantes de espuma.

A gelificação de proteínas globulares tem sido investigada extensivamente e pode ser promovida por meio de tratamentos ácido ou enzimático, por adição de sais, e pela ação de calor [3,4]. Quando induzida pelo calor, a pH neutro, a gelificação de proteínas globulares aparentemente consiste de um processo em duas etapas. Na pri-

Recebido para publicação em 27/02/2004. Aceito para publicação em 25/04/2005 (001297).

Programa de Ciências de Alimentos, Instituto de Macromoléculas Prof Eloisa Mano, Universidade Federal do Rio de Janeiro, Caixa Postal 68525, CEP: 21945-970, Rio de Janeiro, RJ. Fone: (21) 2562 7204. Fax: (21)22701317.E-mail: ctandrade@ima.ufrj.br

A quem a correspondência deve ser enviada. meira etapa, as moléculas sofrem uma transição conformacional ou desnaturação parcial, pela qual o número de resíduos hidrofóbicos expostos ao solvente aquoso aumenta $[1,12,17]$. Como conseqüência, na segunda etapa, as moléculas parcialmente desnaturadas agregam-se. Um gel macroscópico é formado se a concentração de proteína for maior do que um valor crítico $[1,5,18,26]$.

A cinética de agregação e a estrutura dos agregados são ditadas pelo balanço de forças atrativas e repulsivas entre as moléculas de proteína parcialmente desnaturadas e, de modo geral, dependem do $\mathrm{pH}$, o qual controla a carga líquida da proteína e da força iônica, que limita as interações eletrostáticas [2]. A pHs afastados do ponto isoelétrico da proteína e sob força iônica baixa, a repulsão eletrostática entre as moléculas é grande; a rede tridimensional do gel formado (transparente) é constituída por fiadas finas, de diâmetro da ordem de nanômetros $[14,15,22]$. No ponto isoelétrico ou sob força iônica suficiente para eliminar a repulsão eletrostática intermolecular, a rede tridimensional desses géis, denominados de géis particulados (brancos opacos), torna-se menos específica devido à agregação irregular de moléculas e seu diâmetro alcança a ordem de micrômetros [14,23].

Grande parte das informações sobre a gelificação e as propriedades de géis de proteínas globulares foi obtida a partir de estudos com sistemas formados por apenas uma proteína, em particular com a $\beta$-lactoglobulina. Técnicas diversas, como as espectroscópicas, o espalhamento de neutrons a baixo ângulo, o espalhamento de raios-X a baixo ângulo, o espalhamento de luz estático e dinâmico, a cromatografia de exclusão por tamanho, a calorimetria diferencial de varredura, medidas reológicas e técnicas de miscroscopia têm sido usadas, independen- 
temente ou em conjunto, na obtenção dessas informações. No entanto, o mecanismo de desnaturação, agregação e gelificação das proteínas globulares puras e em misturas, como no soro do leite, ainda não foi completamente elucidado [1,12,14,17,20,21,22,23,24].

A gelificação do WPI $[8,13,25]$, assim como as propriedades dos géis resultantes, tem sido pouco investigada por meio de medidas reológicas. Estudos relativos ao WPC não foram encontrados na literatura científica. No entanto, as propriedades funcionais desses produtos, em particular a gelificação, têm contribuído para o seu uso crescente em alimentos [13].

No presente trabalho, o efeito do $\mathrm{pH}$ sobre a gelificação de um concentrado comercial de proteínas do soro do leite, em suspensões a $10 \%(\mathrm{~m} / \mathrm{m})$, foi estudado por meio de medidas reológicas sob cisalhamento oscilatório. Foram obtidas informações sobre a gelificação induzida pelo calor do sistema com uma mistura de proteínas globulares, e sobre o comportamento dos géis formados, sob condições de $\mathrm{pH}$ neutro e ácido. A importância de estudos com concentrados de proteínas deve-se ao fato de que o seu custo e disponibilidade favorecem o seu uso pela indústria de alimentos.

\section{2 - MATERIAL E MÉTODOS}

\section{1 - Material}

O material utilizado consistiu de uma amostra comercial de concentrado de proteínas do soro do leite (WPC), de marca ALACEN ${ }^{\text {" }}$ 450, fornecida pela Probiótica Produtos Naturais Ltda. (São Paulo, SP). De acordo com o fabricante, a amostra usada contém $83,6 \%$ de proteínas, $6,67 \%$ de carboidratos, $7,5 \%$ de lipídios, 0,39\% de cálcio e $0,71 \%$ de sódio. A técnica de fluorescência de raios- $\mathrm{X}$ foi usada para quantificar os minerais presentes no WPC, em espectrômetro de fluorescência de raios-X Rigaku, modelo RIX 3100 (Osaka, Japan). Esse equipamento possui fonte de raios-X de sódio $(4 \mathrm{~kW})$ e a análise é efetuada em pérola preparada a partir das cinzas (1 parte), obtidas pelo aquecimento da amostra a $550^{\circ} \mathrm{C}$ durante $4 \mathrm{~h}$, às quais, tetraborato de lítio é adicionado (10 partes). Por meio dessa técnica, foram quantificados (em mg/100g WPC) os elementos sódio $(153,1)$, magnésio $(45,6)$, silício $(17,8)$, fósforo $(320,0)$, enxofre $(3,8)$, potássio $(738,0)$, cálcio $(547,9)$, ferro $(1,1)$, níquel $(9,2)$ e cobre $(10,9)$. O teor em cinzas foi de $2,8 \%$, semelhante ao reportado na literatura para outras amostras de WPC e de WPI [6].

\section{2 - Métodos}

\subsection{1 - Medidas turbidimétricas}

A absorvância a 650nm em função do $\mathrm{pH}$ (faixa 2,5 a $9,5)$ de suspensões aquosas diluídas de WPC, foi determinada anteriormente a qualquer tratamento térmico, em espectofotômetro Thermolyne Turner modelo SP-870 (Dubuque, USA).

\subsection{2 - Preparação de soluções}

Soluções de WPC foram preparadas a $10 \%(\mathrm{~m} / \mathrm{m})$, sob agitação magnética e temperatura ambiente durante 3h, após a adição controlada do produto à água destilada e deionizada. Uma pequena porção de azida de sódio foi adicionada às soluções, que permaneceram em geladeira durante uma noite. Decorrido esse período, as soluções foram filtradas em papel de filtro e o $\mathrm{pH}$ foi medido. $\mathrm{O} \mathrm{pH}$ original das soluções de WPC, pH 6,53, foi ajustado a pH 7,0 com uma solução $1 \mathrm{~N}$ de $\mathrm{NaOH}$ e a pH 4,6 e 4,0 com uma solução $1 \mathrm{~N}$ de $\mathrm{HCl}$.

\subsection{3 - Medidas reológicas sob cisalhamento osci- latório}

Medidas reológicas sob cisalhamento oscilatório foram realizadas em reômetro de tensão e deformação controladas AR2000, da TA Instruments (New Castle, Delaware, USA), equipado com geometria de placas paralelas de $4,0 \mathrm{~cm}$ de diâmetro e gap de $500 \mu \mathrm{m}$. As soluções foram desgaseificadas sob vácuo e, após a colocação de cada uma das amostras no sistema de medição, a superficie exposta ao ar foi recoberta com óleo mineral, a fim de evitar-se a evaporação do solvente. Inicialmente, as amostras foram condicionadas no reômetro a $20^{\circ} \mathrm{C}$, durante $5 \mathrm{~min}$. Após esse período, as amostras foram aquecidas a $80^{\circ} \mathrm{C}$, sob taxa de $2 \mathrm{C} / \mathrm{min}$. A temperatura foi mantida a $80^{\circ} \mathrm{C}$ durante $3 \mathrm{~h}$, quando então as amostras foram submetidas a uma varredura de freqüência, na faixa $0,06283 \mathrm{a} 200 \mathrm{rad} / \mathrm{s}$. Ao término desse ensaio, a temperatura foi levada a $20^{\circ} \mathrm{C}$, sob taxa de $2{ }^{\circ} \mathrm{C} / \mathrm{min}$. Após um período de $2 \mathrm{~h}$ sob essa temperatura, uma outra varredura de freqüência foi realizada a $20^{\circ} \mathrm{C}$. Durante as etapas de aquecimento, de resfriamento e de condicionamento, as medidas oscilatórias foram realizadas no domínio de comportamento linear, sob freqüência de $6,28 \mathrm{rad} / \mathrm{s}$ e amplitude de deformação de $1 \%$. Finalmente, ensaios oscilatórios com variação da amplitude de deformação na faixa de 0,02 a $100 \%$ foram realizados a $20^{\circ} \mathrm{C}$, sob freqüência de $6,28 \mathrm{rad} / \mathrm{s}$.

\section{3 - RESULTADOS E DISCUSSÃO}

Anteriormente a qualquer tratamento térmico, medidas turbidimétricas a $650 \mathrm{~nm}$, em função do $\mathrm{pH}$, foram realizadas com suspensões diluídas de WPC. Um valor máximo foi determinado a $\mathrm{pH} 4,6$. Esse resultado indicou a presença de agregados na faixa de $\mathrm{pH}$ entre 3,0 e 5,2 .

No presente trabalho, as medidas reológicas foram realizadas em água a $\mathrm{pH} 4,6$, condição em que a agregação mostrou-se máxima, e a pH 7,0, quando as proteínas encontradas em maior proporção no soro estão carregadas negativamente. As medidas foram também realizadas a $\mathrm{pH} 4,0$, valor de $\mathrm{pH}$ inferior ao ponto isoelétrico das proteínas majoritárias, e condição na qual a agregação significativa foi observada por meio de medidas turbidimétricas. 

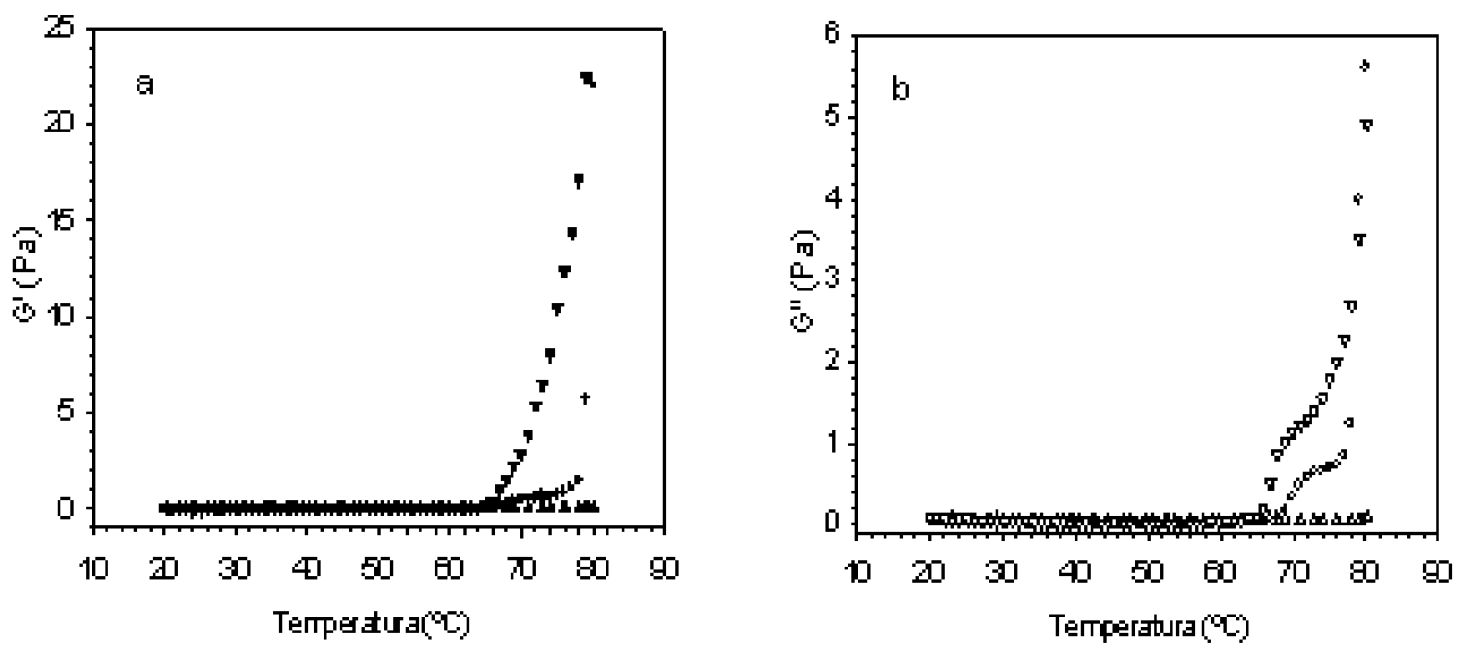

FIGURA 1 - Variação de G' (a) e de G" (b) em função do aumento da temperatura a $2{ }^{\circ} \mathrm{C} / \mathrm{min}$ de suspensões de WPC a $10 \%$ (m/m) em água; $\boldsymbol{\Lambda}, \triangle, \mathrm{pH} 7,0 ; \bigcirc, \bigcirc, \mathrm{pH} 4,6 ; \boldsymbol{\nabla}, \nabla, \mathrm{pH} 4,0$

As Figuras 1a e $1 b$ mostram a variação dos módulos de armazenamento, G', e do módulo de perda, G", respectivamente, em função do aumento na temperatura, de 20 a $80^{\circ} \mathrm{C}$, sob taxa de $2 \mathrm{C} / \mathrm{min}$, para suspensões de WPC a $10 \%(\mathrm{w} / \mathrm{w})$ em água nas três diferentes condições de $\mathrm{pH}$. Em todos os três casos, no início do experimento, os valores de G" são ligeiramente superiores aos baixos valores de $\mathrm{G}^{\prime}$. O aquecimento até $65^{\circ} \mathrm{C}$, sob as condições usadas, aparentemente não alterou ou aumentou a proporção de agregados a ponto de afetar os valores de G'. A partir de $65^{\circ} \mathrm{C}$, para a suspensão a $\mathrm{pH} 4,0$, os valores de $\mathrm{G}^{\prime}$ passaram a sofrer aumento contínuo com o aumento da temperatura, quando chegaram a ultrapassar G". O ponto em que $\mathrm{G}^{\prime}$ = G" tem sido considerado como o ponto gel. $\mathrm{O}$ mesmo comportamento pode ser observado para as amostras a $\mathrm{pH}$ 4,6 e 7,0, com diferenças nas temperaturas nas quais ocorreu o aumento rápido em ambos os módulos e o ponto gel foi observado. A pH 7,0, só após alcançar $80^{\circ} \mathrm{C}$, um aumento significativo nos valores de $\mathrm{G}^{\prime}$ e de G" foi observado. Para uma amostra de WPI a 110g/L em água e no mesmo $\mathrm{pH}$, e submetida a experimento semelhante, o aumento de G' e de G" foi observado após a elevação da temperatura a $80^{\circ} \mathrm{C}$ [10]. A maior estabilidade térmica sob condições de $\mathrm{pH}$ mais elevado do que o ponto isoelétrico foi observada para a ovalbumina [11] e para a albumina do soro bovino (BSA) [27] em soluções aquosas de $\mathrm{NaCl}$, por calorimetria diferencial de varredura.

Diferentemente do comportamento a $\mathrm{pH} 4,0$ e a $\mathrm{pH}$ 7,0 , sob condições de $\mathrm{pH} 4,6$, um aumento pequeno em $\mathrm{G}^{\prime}$ e G" foi observado na faixa de temperatura entre $\sim 67 \mathrm{e}$ $76^{\circ} \mathrm{C}$ e, só então, ocorreu o aumento rápido nos valores de ambos os módulos. No entanto, o ponto em que G' = G" foi alcançado a $67^{\circ} \mathrm{C}$. Como o valor de $\mathrm{G}^{\prime}$ é ainda muito baixo, é razoável supor-se que, a essa temperatura, um estado pré-gel tenha sido alcançado, com a formação da rede tridimensional a temperaturas mais elevadas. De acordo com a literatura, para a $\beta$-lactoglobulina, géis particulados são formados em faixa intermediária de $\mathrm{pH}$ (4 a 6) e, para misturas de proteínas, como as do soro do leite, o mesmo tipo de rede tridimensional é formado em faixa intermediária de $\mathrm{pH}$, mas em intervalo mais largo [23]. A técnica de microscopia de força atômica (AFM) foi usada para investigar a morfologia de agregados de WPI, a pH 2 e a $\mathrm{pH} 7$; apenas a $\mathrm{pH} 2$, os agregados foram caracterizados como fibrilares [14]. No presente caso, todos os géis apresentaram coloração branca opaca, muito provavelmente devido à presença de sais no WPC, e podem ser considerados particulados.

A Figura 2 mostra a cinética de gelificação a $80^{\circ} \mathrm{C}$ para suspensões de WPC a $10 \%(\mathrm{~m} / \mathrm{m})$ em água sob diferentes condições de $\mathrm{pH}$. A $80^{\circ} \mathrm{C}$, o processo de gelificação tem continuidade, com aumentos significativos de $\mathrm{G}^{\prime} \mathrm{e}$ de G". Seria interessante ressaltar que a $\mathrm{pH} 4,0$ e a $\mathrm{pH}$ 7,0 , esses valores não alcançaram um valor de equilíbrio durante as 3 h de experimento. No entanto, a pH 4,6, G' alcançou um platô após aproximadamente $2 \mathrm{~h}$. Para a BSA, na faixa de concentração entre 10 a $230 \mathrm{mg} / \mathrm{mL}$, sob condições isoelétricas, a uma freqüência de 6,28rad/s e amplitude de deformação de 1\%, G' e G" atingiram um platô após $4 \mathrm{~h}$ de aquecimento a $80^{\circ} \mathrm{C}$ [16].

Os géis produzidos pelo calor de proteínas do soro do leite são estabilizados por interações hidrofóbicas, pontes de hidrogênio, interações eletrostáticas e por ligações covalentes [19]. A formação de ligações covalentes intermoleculares, de maior energia, e que mais contribuem pa- 


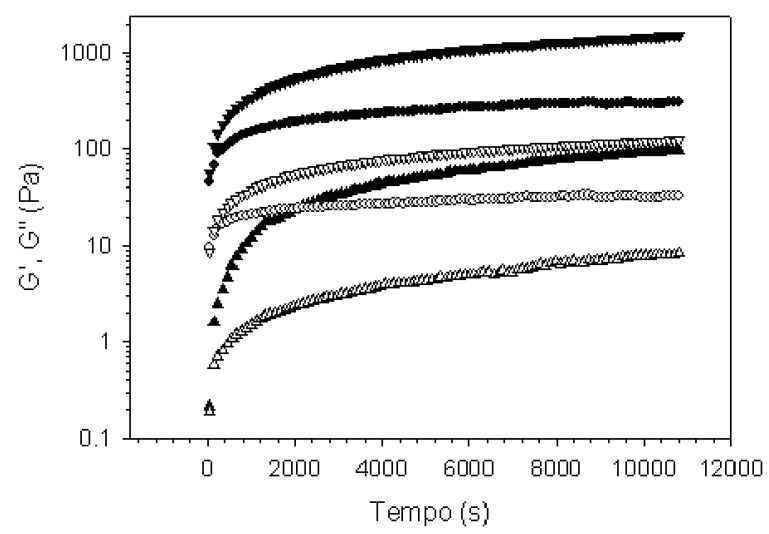

FIGURA 2 - Cinética de gelificação a $80^{\circ} \mathrm{C}$ de suspensões de WPC a $10 \%(\mathrm{~m} / \mathrm{m})$ em água; $\boldsymbol{\Lambda}, \triangle, \mathrm{pH} 7,0 ; \boldsymbol{O}, \mathrm{O}, \mathrm{pH} 4,6 ; \boldsymbol{\nabla}$, $\nabla, \mathrm{pH} 4,0$. Símbolos cheios, G'; simbolos vazios, G"

ra o caráter elástico do gel, resultam da exposição de grupos tiol (sulfidrila) reativos, que formam ligações do tipo dissulfeto com outros grupos tiol,ou sofrem reações de troca com grupos dissulfeto presentes na $\beta$ lactoglobulina, na $\alpha$-lactalbumina e na albumina do soro do leite. No entanto, a formação de tais ligações ocorre preferencialmente a $\mathrm{pH}$ neutro e praticamente não se dá a pH ácido [2].

Os resultados da Figura 2 mostram valores de G' e de G" bem mais elevados para o gel formado a partir de suspensões a pH 4,0, condição menos favorável à reatividade dos grupos tiol [2], em relação às demais condições de $\mathrm{pH}$ usadas no presente estudo. Em experimentos realizados com suspensões de WPI a 13\%, a pH 5 e a pH 7, o pseudo-platô não só foi atingido mais rapidamente a $\mathrm{pH}$, como também os valores de G' foram mais elevados [25]. Os resultados obtidos no presente trabalho parecem indicar que, para o concentrado de proteínas, no qual uma quantidade significativa de sais está presente, a formação de ligações hidrofóbicas em soluções aquosas, que é favorecida pelo aquecimento e pelo decréscimo do $\mathrm{pH}$, tem papel mais importante na estabilização do gel de maior G', a pH 4,0. Essa interpretação é baseada nas evidências acumuladas em relação à estabilização da conformação terciária de proteínas globulares, para a qual as interações hidrofóbicas são consideradas dominantes [7].

A Figura 3 apresenta os espectros mecânicos obtidos a $80^{\circ} \mathrm{C}$ e amplitude de eformação de $1 \%$, na faixa de freqüência entre 0,06283 e 200rad/s. Nas condições de pH estudadas, os respectivos espectros apresentam semelhanças qualitativas; G' e G" variam relativamente pouco com a freqüência e os valores de $G$ " permanecem bem menores do que os de G'. As variações de G' e de G", dentro da escala logarítmica, assim como o ângulo de perda, $\operatorname{tg} \delta$
= G" $/ \mathrm{G}^{\prime}$ menor do que 0,1 para os géis formados sob condições de pH 4,0, confirmam o seu caráter elástico mais marcante. As flutuações de G" observadas sob freqüências baixas, principalmente para o gel a $\mathrm{pH} 7,0$, podem estar relacionadas ao seu caráter viscoso, comumente observado para géis de proteinas.

As Figuras $4 a$ e $4 b$ mostram a variação de G' e de G", respectivamente, com o decréscimo da temperatura de 80 a 20 C. Para os géis de suspensões preparadas a $\mathrm{pH}$ 7,0 e 4,6, um pequeno aumento nos valores de G' e de G" pode ser observado.

Um aumento muito mais expressivo ocorreu no caso dos géis obtidos a partir de suspensões preparadas sob condições de $\mathrm{pH} 4,0$. Com o decréscimo da temperatura, a formação de pontes de hidrogênio é favorecida; os géis tornam-se mais fortes, e G' e G" aumentam. No caso da gelificação induzida pelo calor de WPC a pH 4,0, o aumento bem maior de G' pode ser atribuído à formação, pelo resfriamento, de pontes de hidrogênio intermoleculares na rede tridimensional anteriormente estruturada e fortalecida por ligações hidrofóbicas.

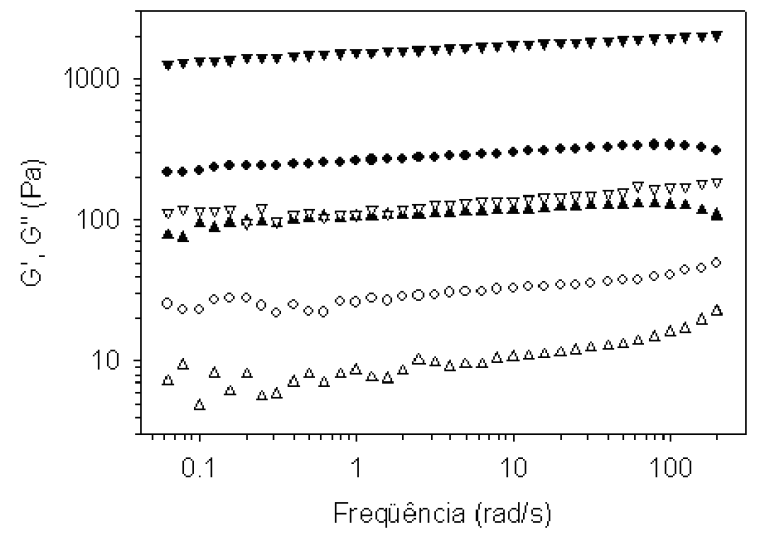

FIGURA 3 - Espectros mecânicos a $80^{\circ} \mathrm{C}$ de suspensões de géis de WPC a $10 \%(\mathrm{~m} / \mathrm{m})$ em água; $\boldsymbol{\Delta}, \triangle, \mathrm{pH} 7,0 ; \boldsymbol{\ominus}, \bigcirc, \mathrm{pH} 4,6$; $\boldsymbol{\nabla}, \nabla, \mathrm{pH} 4,0$. Simbolos cheios, G'; simbolos vazios, $\mathrm{G}^{\prime \prime}$

Após um período de estabilização de $2 \mathrm{~h}$ a $20^{\circ} \mathrm{C}$ (Figura 5), espectros mecânicos foram obtidos sob essa temperatura (Figura 6). Comparado ao espectro da Figura 3, os valores de G' e de G" a $20^{\circ} \mathrm{C}$ são bem maiores e variam pouco com a freqüência. O aumento dos módulos foi maior no caso dos géis da suspensão de WPC a pH 7,0, quando comparado àqueles a $\mathrm{pH} 4,6$. Nesse caso, os resultados parecem indicar que, com o decréscimo da temperatura e a formação de pontes de hidrogênio, as estruturas dos géis obtidos a partir de suspensões de WPC a pH 7,0 e a pH 4,6 aparentemente tendem a igualar-se. No entanto, a $20^{\circ} \mathrm{C}$ o menor valor de $\operatorname{tg} \delta \sim 0,06 \mathrm{apH} 7,0$ indica que, dentre as condições estudadas de $\mathrm{pH}$, esse gel apre- 

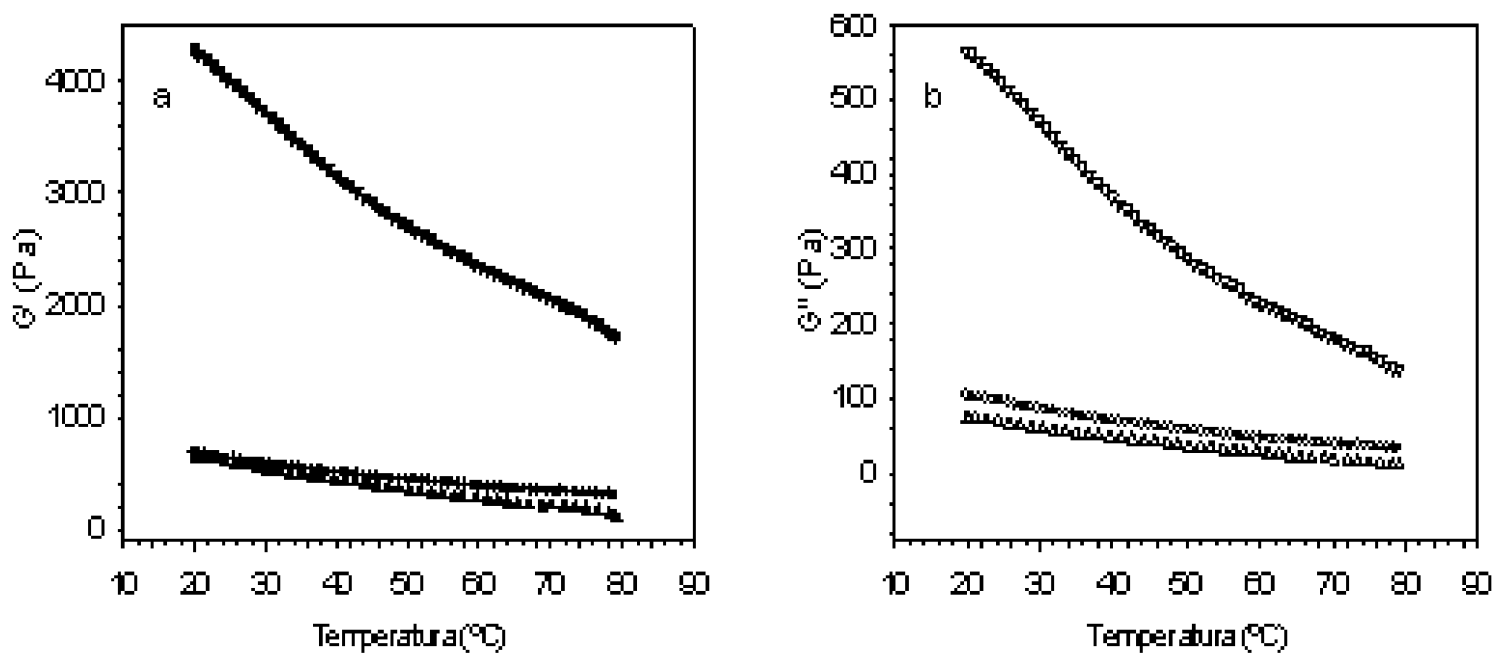

FIGURA 4 - Variação de G' (a) e de G" (b) em função do decréscimo da temperatura a $2^{\circ} \mathrm{C} / \mathrm{min}$ de suspensões de WPC a $10 \%$ (m/m) em água; $\mathbf{\Lambda}, \triangle, \mathrm{pH} 7,0 ; \mathbf{O}, \bigcirc, \mathrm{pH} 4,6 ; \boldsymbol{\nabla}, \nabla, \mathrm{pH} 4,0$

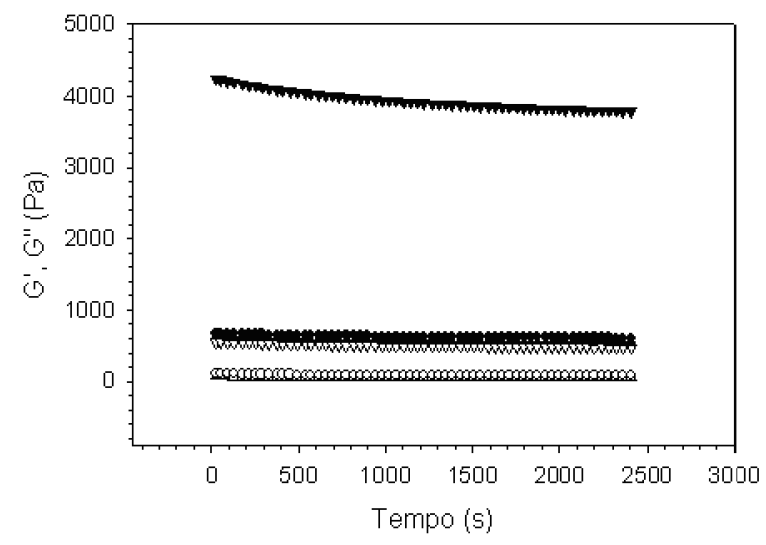

FIGURA 5 - Cinética de gelificação a $20^{\circ} \mathrm{C}$ de géis de WPC a $10 \%$ $(\mathrm{m} / \mathrm{m})$ em água; $\boldsymbol{\Delta}, \triangle, \mathrm{pH} 7,0 ; \bigcirc, \bigcirc, \mathrm{pH} 4,6 ; \boldsymbol{\nabla}, \nabla, \mathrm{pH} 4,0$. Símbolos cheios, G'; simbolos vazios, G"

senta o caráter elástico mais elevado. O decréscimo no valor de $\operatorname{tg} \delta$ com a queda da temperatura de $80^{\circ} \mathrm{C}$ para $20^{\circ} \mathrm{C}$, observado para uma amostra de WPI, foi relacionado à existência de rede de fiada fina [25] .

As diferenças estruturais entre os géis de WPC podem ainda ser conferidas a partir dos experimentos realizados em seguida aos espectros mecânicos a $20^{\circ} \mathrm{C}$. Nesses ensaios, os géis foram submetidos a amplitudes

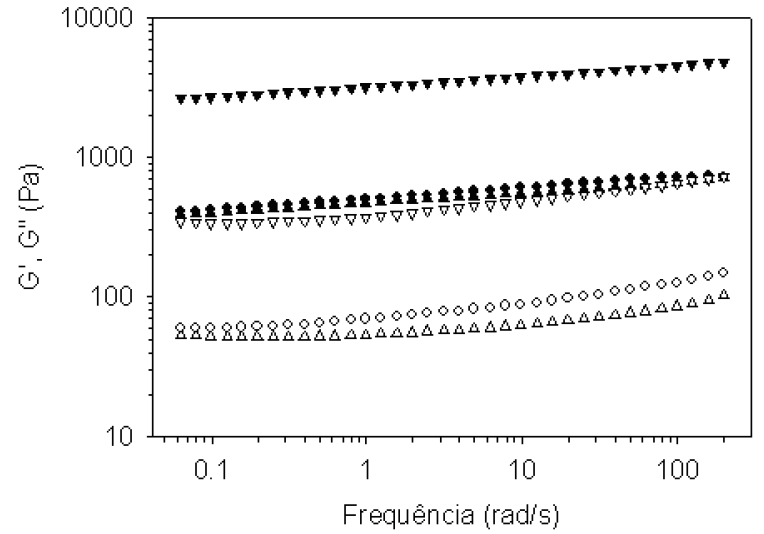

FIGURA 6 - Espectros mécânicos a $20^{\circ} \mathrm{C}$ de géis de WPC a $10 \%$ $(\mathrm{m} / \mathrm{m})$ em água; $\boldsymbol{\Delta}, \triangle, \mathrm{pH} 7,0 ; \bigcirc, \bigcirc, \mathrm{pH} 4,6 ; \boldsymbol{\nabla}, \nabla, \mathrm{pH} 4,0$. Simbolos cheios, G'; símbolos vazios, G"

de deformação crescentes, na faixa entre 0,02 a $100 \%$, a $20^{\circ} \mathrm{C}$. A Figura 7 mostra a variação de G'/G'. em função da amplitude de deformação, para os géis de WPC a diferentes $\mathrm{pH}$. Os géis a $\mathrm{pH} 4,6$ suportam apenas deformações baixas, até o limite de $1 \%$, acima do qual o comportamento viscoelástico linear não mais é observado. Por outro lado, a faixa de comportamento viscoelástico linear estende-se até, aproximadamente, $4 \%$ para os géis a $\mathrm{pH}$ 7,0 e a $\mathrm{pH} 4,0$. De acordo com a Figura 7 , embora 
apresente o mesmo limite de deformação elástica observado para o gel obtido a $\mathrm{pH} 4,0$, o gel a $\mathrm{pH}$ 7,0 mantêm-se mais próximo à linearidade sob deformações elevadas.

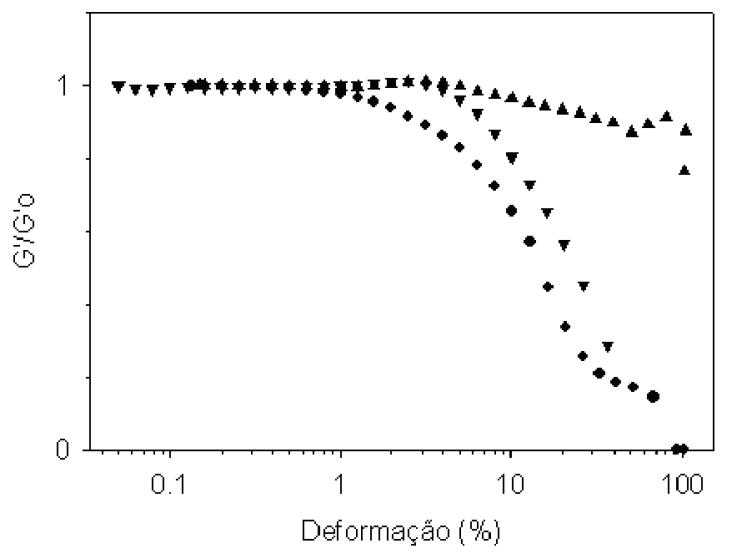

FIGURA 7 - Módulo de armazenamento reduzido ( $G^{\prime} / G^{\prime}$.) em função da amplitude de deformação a $20^{\circ} \mathrm{C}$ de géis de WPC a

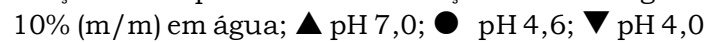

\section{4 - CONCLUSÕES}

O estudo reológico sob cisalhamento oscilatório realizado com suspensões de proteínas do soro do leite (WPC) a 10\% (m/m) em água, a diferentes condições de $\mathrm{pH}$, mostrou (a) que a concentração usada foi suficiente para que ocorresse formação de géis macroscópicos sob todas as condições usadas de $\mathrm{pH}$; (b) que o pH exerce um papel importante sobre a temperatura crítica de gelificação e sobre as propriedades viscoelásticas dos géis curados a 80 e a $20^{\circ} \mathrm{C}$. A pH 4,0, o processo de gelificação induzido pelo calor teve início a $65^{\circ} \mathrm{C}$ e, após a cinética de gelificação a $80^{\circ} \mathrm{C}$, foi formado o gel mais rígido e de caráter elástico mais elevado, estabilizado por interações hidrofóbicas. Com o resfriamento a $20^{\circ} \mathrm{C}$, um aumento significativo nos valores de G' e de G" foi observado; o efeito da formação de pontes de hidrogênio revelou-se marcante. A pH 7,0, a suspensão mostrou-se mais estável ao calor. O processo de gelificação teve início a $80^{\circ} \mathrm{C}$ e o gel menos rígido e de menor caráter elástico foi caracterizado, após a establização a $80^{\circ} \mathrm{C}$. A pH 4,6, o cruzamento dos módulos deu-se a $67^{\circ} \mathrm{C}$, mas o aumento acentuado de G' só foi observado a $76^{\circ} \mathrm{C}$. O gel curado a $80^{\circ} \mathrm{C}$ apresentou valores intermediários de $\mathrm{G}^{\prime}$. Espectros mecânicos realizados a $20^{\circ} \mathrm{C}$ mostraram características viscoelásticas aparentemente semelhantes para os géis a $\mathrm{pH} 7,0$ e a pH 4,6. No entanto, o gel obtido a $\mathrm{pH} 7,0$ foi aquele que apresentou o caráter elástico mais elevado e demonstrou a menor sensibilidade à deformação sob essa temperatura, muito provavelmente devido à formação favorecida de ligações covalentes.

\section{5 - REFERÊNCIAS BIBLIOGRÁFICAS}

[1] AYMARD, P.; GIMEL, J.C.; NICOLAI, T.; DURAND, D. Experimental evidence for a two-step process in the aggregation of $\beta$-lactoglobulin at $\mathrm{pH} 7$, J. Chim. Phys. PCB, v. 93, n. 5, p. 987-997, 1996.

[2] AYMARD, P.; NICOLAI, T.; DURAND, D.; CLARK, A. Static and dynamic scattering of $\beta$-lactoglobulin aggregates formed after heat-induced denaturation at $\mathrm{pH} 2$. Macromolecules, v. 32, n. 8, p. 2542-2552, 1999.

[3] CLARK, A.H.; LEE-TUFFNELL, C.D. Small-angle X-ray scattering studies of thermally-induced globular protein gels. Int. J. Pept. Prot., v. 16, n. 4, p. 339-351, 1980.

[4] CLARK, A.H., LEE-TUFFNELL, C.D. Gelation of globular proteins. In: Mitchell, J.R.; Ledward, D.A. (eds.) Functional proteins of food macromolecules. Elsevier Applied Science, 1986, London, pp. 203-272.

[5] CLARK, A.H.; ROSS-MURPHY, S.B. Structural and mechanical properties of biopolymer gels; Adv. Polymer Sci., v. 83, p. 57-192, 1987.

[6] DE WIT, J.N.; VAN KESSEL, Th. Effects of ionic strength on the solubility of whey protein products. A colloid chemical approach. Food Hydrocoll., v. 10, n. 2, p. 143149, 1996.

[7] DILL, K.A. Dominant forces in protein folding. Biochemistry, v. 29, n. 3, p. 7133-7155, 1990.

[8] FERNANDES, P.B. Viscoelastic characteristics of whey protein systems at neutral pH. Food Hydrocoll., v. 8, n. 3, p. 277-285, 1994.

[9] FOEGEDING, E.A.; DAVIS, J.P.; DOUCET, D., McGUFFEY, M.K. Advances in modifying and understanding whey protein functionality, Trends Food Sci. Technol., v. 13, n. 5, p. 151-159, 2002.

[10] GONÇALVES, M.P.; TORRES, D.; ANDRADE, C.T.; AZERO, E.G.; LEFEBVRE, J. Rheological study of the effect of Cassia javanica galactomannans on the heat-set gelation of a whey protein isolate at $\mathrm{pH}$ 7. Food Hydrocoll., v. 18, n. 2, 181-189, 2004.

[11] HAGOlLE, N.; RELKIN, P.; DALGLEISH, D.G.; LAUNAY, B. Transition temperatures of heatinduced structural changes in ovalbumin solutions at acid and neutral $\mathrm{pH}$. Food Hydrocoll., v. 11, n. 3, p. 311-317, 1997.

[12] IAMETTI, S.; DE GREGORI, B.; VECCHIO, G.; BONOMI, F. Modifications occur at different structural levels during heat denaturation of $\beta$-lactoglobulin. Eur. J. Biochem., v. 237, n. 1, p. 106-112, 1996.

[13] IKEDA, S. Heat-induced gelation of whey proteins observed by rheology, atomic force microscopy, and Raman Scattring spectroscopy. Food Hydrocoll., v. 17, n. 4, p. 399-406, 2003.

[14] IKEDA, S.; MORRIS, V.J. Fine-stranded and particle aggregates of heat-denatured whey proteins visualized by atomic force microscopy. Biomacromolecules, v. 3, n. 2, p. 382-389, 2002.

[15] KAVANAGH, G.M.; CLARK, A.H.; ROSS-MURPHY, S.B. Heat-induced gelation of globular proteins: Part 3 . Molecular studies on low $\mathrm{pH} \beta$-lactoglobulin gels. Int. J. Biol. Macromol., v. 28, n. 1, p. 41-50, 2000. 
[16] LEFEBVRE, J.; RENARD, D.; SANCHEZ-GIMENO, A.C. Structure and rheology of heat-set gels of globular proteins. I. Bovine serum albumin gels in isoelectric conditions. Rheol. Acta, v. 37, n. 4, p. 345-357, 1998.

[17] RELKIN, P. Reversibility of heat-induced conformational changes and surface exposed hydrophobic clusters of $\beta$ lactoglobulin: their role in heat-induced sol-gel state transition. Int. J. Biol. Macromol., v. 22, n. 1 , p. 59-66, 1998.

[18] RENARD, D.; LEFEBVRE, J. Gelation of globular proteins: effect of $\mathrm{pH}$ and ionic strength on the critical concentration for gel formation. A simple model and its application to $\beta$-lactoglobulin heat-induced gelation. Int. J. Biol. Macromol., v. 14, n. 5, p. 287-291, 1992.

[19] SCHOKKER, E.P.; SINGH, H.; PINDER, D.N.; NORRIS, G.E.; CREAMER, L.K. Characterization of intermediates formed during heat-induced aggregation of $\beta$ lactoglobulin $\mathrm{AB}$ at neutral pH. Int. Dairy J., v. 9, n. 11, p. 791-800, 1999.

[20] STADING, M.; HERMANSSON, A.-M. Viscoelastic behaviour of $\beta$-lactoglobulin gel structures. Food Hydrocoll., v. 4, n. 2, p. 121-135, 1990.

[21] STADING, M.; HERMANSSON, A.-M. Large deformation properties of $\beta$-lactoglobulin gel structures. Food Hydrocoll., v. 5, n. 4, p. 339-352, 1991.

[22] STADING, M.; LANGTON, M.; HERMANSSON, A.-M.; Inhomogeneous fine-stranded $\beta$-lactoglobulin gels. Food Hydrocoll., v. 6, n. 5, p. 455-470, 1992.
[23] STAding, M.; LANGTON, M.; HERMANSSON, A.-M. Microstructure and rheological behaviour of particulate $\beta$-lactoglobulin gels. Food Hydrocoll., v. 7, n. 3, p. 195212, 1993.

[24] STADinG, M; LANGTON, M.; HERMANSSON, A.-M. Small and large deformation studies of protein gels. $\mathbf{J}$. Rheol., v. 39, n. 6, p, 1445-1450, 1995.

[25] TAVARES, C; LOPES DA SILVA, J.A. Rheology of galactomannan-whey protein mixed systems. Int. Dairy J., v. 13, n. 8, p. 699-706, 2003.

[26] TOBITANI, A.; ROSS-MURPHY, S:B. Heat-induced gelation of globular proteins. 1. Model for the effects of time and temperature on the gelation time of BSA gels. Macromolecules, v. 30, n. 17, p. 4845-4854, 1997.

[27] YAMASAKI, M.; YANO, H.; AOKI, K. Differential scanning calorimetric studies on bovine serum albumin: I. Effects of $\mathrm{pH}$ and ionic strength. Int. J. Biol. Macromol., v. 12, n. 4, p. 263-268, 1990.

\section{6 - AGRADECIMENTOS}

Os autores agradecem ao CNPq e a CAPES (Projeto CAPES/GRICES 092/02) pelo apoio financeiro, ao CENPES-PETROBRAS, pela permissão para o uso do reômetro AR2000 e ao NUCAT/COPPE/UFRJ pela análise do WPC por meio de fluorescência de raios-X. 